Article

\title{
Engineering of Yeast Old Yellow Enzyme OYE3 Enables Its Capability Discriminating of (E)-Citral and (Z)-Citral
}

\author{
Tairan Wang ${ }^{1,+}$, Ran Wei ${ }^{1,+}$, Yingting Feng ${ }^{1}$, Lijun Jin ${ }^{1}$, Yunpeng Jia ${ }^{1}$, Duxia Yang ${ }^{1}$, Zuonan Liang ${ }^{1}$, \\ Mengge Han ${ }^{1}, \mathrm{Xia} \mathrm{Li}^{1}$, Chenze Lu ${ }^{2}$ and Xiangxian Ying ${ }^{1, * \mathbb{D}}$
}

1 Key Laboratory of Bioorganic Synthesis of Zhejiang Province, College of Biotechnology and Bioengineering, Zhejiang University of Technology, Hangzhou 310014, China; 13591715817@163.com (T.W.); weiranzjut@163.com (R.W.); fengyingting2021@163.com (Y.F.); jinlijun130@163.com (L.J.); ddbbjjpp123@163.com (Y.J.); Y1936279940@163.com (D.Y.); znznlcccc@163.com (Z.L.); a13072676126@163.com (M.H.); lixia970419@163.com (X.L.)

2 College of Life Sciences, China Jiliang University, Hangzhou 310018, China; chenzelu@cjlu.edu.cn

* Correspondence: yingxx@zjut.edu.cn; Tel.: +86-571-88320781

+ These authors contributed equally to this work.

\section{check for} updates

Citation: Wang, T.; Wei, R.; Feng, Y.; Jin, L.; Jia, Y.; Yang, D.; Liang, Z.; Han, M.; Li, X.; Lu, C.; et al. Engineering of Yeast Old Yellow Enzyme OYE3

Enables Its Capability Discriminating of (E)-Citral and (Z)-Citral. Molecules 2021, 26, 5040. https://doi.org/ $10.3390 /$ molecules 26165040

Academic Editors: Valéria de

Carvalho Santos Ebinuma and Ana Paula Tavares

Received: 20 July 2021

Accepted: 17 August 2021

Published: 20 August 2021

Publisher's Note: MDPI stays neutral with regard to jurisdictional claims in published maps and institutional affiliations.

Copyright: (c) 2021 by the authors. Licensee MDPI, Basel, Switzerland. This article is an open access article distributed under the terms and conditions of the Creative Commons Attribution (CC BY) license (https:// creativecommons.org/licenses/by/ $4.0 /)$.

\begin{abstract}
The importance of yeast old yellow enzymes is increasingly recognized for direct asymmetric reduction of $(E / Z)$-citral to $(R)$-citronellal. As one of the most performing old yellow enzymes, the enzyme OYE3 from Saccharomyces cerevisiae S288C exhibited complementary enantioselectivity for the reduction of $(E)$-citral and $(Z)$-citral, resulting in lower e.e. value of $(R)$-citronellal in the reduction of $(E / Z)$-citral. To develop a novel approach for the direct synthesis of enantio-pure $(R)$ citronellal from the reduction of $(E / Z)$-citral, the enzyme OYE3 was firstly modified by semi-rational design to improve its $(R)$-enantioselectivity. The OYE3 variants W116A and S296F showed strict $(R)$ enantioselectivity in the reduction of $(E)$-citral, and significantly reversed the $(S)$-enantioselectivity in the reduction of $(Z)$-citral. Next, the double substitution of OYE3 led to the unique variant S296F/W116G, which exhibited strict $(R)$-enantioselectivity in the reduction of $(E)$-citral and $(E / Z)$ citral, but was not active on (Z)-citral. Relying on its capability discriminating (E)-citral and (Z)-citral, a new cascade reaction catalyzed by the OYE3 variant S296F/W116G and glucose dehydrogenase was developed, providing the enantio-pure $(R)$-citronellal and the retained $(Z)$-citral after complete reduction of $(E)$-citral.
\end{abstract}

Keywords: old yellow enzyme; glucose dehydrogenase; (R)-citronellal; (E)-citral; (Z)-citral; asymmetric reduction; resolution

\section{Introduction}

$(R)$-citronellal serves as the key intermediate in the synthesis of L-menthol, which is one of the most popular flavors in the world [1-4]. The industrial production of $(R)$ citronellal is currently synthesized through chemical approaches starting from myrcene (Takasago company in Japan) or citral (BASF company in Germany). In the Takasago method, myrcene is converted to geranylamine, then geranylamine is isomerized and hydrolyzed to form $(R)$-citronellal $[5,6]$. The BASF method is simpler, in which $(E / Z)$-citral is distilled to obtain high-purity $(E)$-citral and then $(R)$-citronellal is synthesized through asymmetric hydrogenation of $(E)$-citral $[7,8]$. Chemical methods employ metal catalysts at elevated temperatures and in organic solvents, which is accompanied with undesired economic and environmental impacts. Meanwhile, biocatalysis is currently recognized as a promising alternative, considering the demands of modern organic synthesis $[9,10]$. Specifically, one-step synthesis of $(R)$-citronellal through enzymatic asymmetric hydrogenation of $(E / Z)$-citral is the most desired in the industry $[8,11]$. Old yellow enzymes (OYEs) are capable of catalyzing the $C=C$ bond reduction of $\alpha, \beta$-unsaturated compounds such as (E)-citral and (Z)-citral [12,13]. Natural (E/Z)-citral was the crude mixture of $\sim 60 \%$ 
(E)-citral and $\sim 40 \%$ (Z)-citral [14]. Unfortunately, the reduction of (E)-citral and (Z)-citral by the same native OYE usually yielded the enantio-complementary products, so the e.e. value of the product from the reduction of $(E / Z)$-citral was often relatively low $[11,15]$.

Protein engineering has been proved to be powerful for overcoming the deficiencies of native OYEs, and successful examples of the improvement of enantioselectivity are accumulating [16-19]. Site-directed mutagenesis technique was widely used for the modification of OYEs, and various key residues determining the enantioselectivity were reported, including W116 and F296 in OYE1 [20-22], Y78, I113, and F247 in OYE2.6 [23]; C26, I69, and H167 in ene reductases YqjM [24]; W100 in OYE from Gluconobacter oxydans (Gox0502); and W66 in NCR ene reductase $[25,26]$. The common strategy engineering the enantioselectivity of OYEs in citral reduction was to change the substrate-binding mode, enabling one citral isomer to bind with a flipped orientation, while maintaining the orientation of the other citral isomer similar to the wild-type enzyme [17]. In old yellow enzyme OYE2y, the double substitutions of R330H/P76M, P76G/R330H, and P76S/R330H improved $(R)$-enantioselectivity to $>99 \%$ e.e. in the reduction of $(E)$-citral or $(E / Z)$-citral [11]. Remarkably, those variants also enabled $(Z)$-citral to bind with a flipped orientation in the active site, and thus reversed (S)-enantioselectivity ( $32.66 \%$ e.e.) to $(R)$-enantioselectivity $(\sim 75 \%$ e.e. $)$. To the best of our knowledge, no OYE variant was reported to reverse $(S)$-enantioselectivity to strict $(R)$-enantioselectivity ( $>99 \%$ e.e.), yet, demonstrating that direct synthesis of enatio-pure $(R)$-citronellal from the asymmetric reduction of $(E / Z)$-citral remained challenging. Besides the change of the substrate-binding mode, a novel strategy relying on the utilization difference of $(E)$-citral and $(Z)$-citral could be attempted to improve $(R)$-enantioselectivity. Yeast OYEs exhibited the opposite enantioselectivity in the asymmetric reduction of $(E)$-citral and $(Z)$-citral, demonstrating $(R)$-enantioselectivity and (S)-enantioselectivity, respectively [11]. It is reasonable to expect that the $(R)$-enantioselectivity of yeast OYEs would be increased if the utilization of (Z)citral was diminished or even abolished. On the other hand, disabling the reduction of (Z)-citral could simultaneously lead to two isomer: enantio-pure $(R)$-citronellal from the reduction of $(E)$-citral and the retained $(Z)$-citral, both of which are valuable for perfume production and organic synthesis [27].

In contrast to bacterial OYEs with preference of $(S)$-enantioselectivity, yeast OYEs are usually afforded to $(R)$-enantiomer in the reduction of $(E / Z)$-citral [28]. Yeast OYE1, OYE2, and OYE3 are the most performing members of this enzyme class [29], whereas no attempt of protein engineering has ever been reported for OYE3, implying that OYE3 has great potential of exploration. Here, aiming to develop a novel approach for the direct synthesis of enantio-pure $(R)$-citronellal from the reduction of $(E / Z)$-citral, the enzyme OYE3 was engineered through the modification of both the substrate-binding mode and the substrateutilization mode. The resulting OYE3 variant discriminating $(E)$-citral and $(Z)$-citral was used to cascade asymmetric reduction of $(E)$-citral and glucose dehydrogenase (GDH)catalyzed NADPH regeneration (Scheme 1 ), affording to the synthesis of enantio-pure $(R)$-citronellal and the retention of $(Z)$-citral.

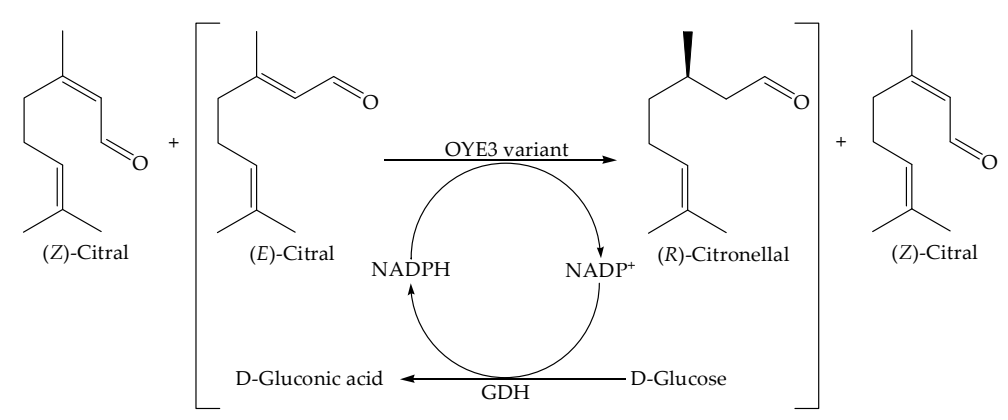

Scheme 1. The OYE3 variant-mediated reduction of $(E / Z)$-citral to $(R)$-citronellal and the retained $(Z)$-citral with the assistance of glucose dehydrogenase-catalyzed NADPH regeneration. 


\section{Results and Discussion}

\subsection{Identification of Key Residues for the Enantioselectivity of OYE3}

The enzyme OYE3 had the opposite enantioselectivity in the asymmetric reduction of $(E)$-citral and $(Z)$-citral, whose corresponding e.e. values were $63.45 \%(R)$ and $47.22 \%$ $(S)$, respectively (Table 1$)$. Thus, the e.e. values for the reduction of $(E / Z)$-citral was lower than that for the reduction of $(E)$-citral. To improve the $(R)$-enantioselectivity in the reduction of $(E / Z)$-citral, site-directed mutagenesis was conducted to test whether key residues critical for other OYEs determined the enantioselectivity of OYE3 [20-26]. OYE3 and its 12 variants were expressed in Escherichia coli and purified for the evaluation of catalytic performance (Figure S1). According to the change in the enantioselectivity, the variants could be classified into three groups. The variants W116A, S296F, H329R, and $\mathrm{R} 38 \mathrm{H}$ showed improved $(R)$-enantioselectivity, whereas the variants $\mathrm{I75C}, \mathrm{P} 77 \mathrm{C}$, and V113A resulted in improved (S)-enantioselectivity, suggesting that the enantioselectivity of OYE3 was not determined by a single amino acid residue. Besides, all the other tested variants showed similar enantioselectivity to that of OYE3.

Table 1. The catalytic performances of OYE3 and its variants with single substitution at putative key residues ${ }^{1}$.

\begin{tabular}{ccccccc}
\hline \multirow{2}{*}{ Enzyme } & \multicolumn{2}{c}{$(E)$-Citral } & \multicolumn{2}{c}{ (Z)-Citral } & \multicolumn{2}{c}{$(E / Z)$-Citral } \\
\cline { 2 - 6 } & e.e. $(\%)$ & Conversion (\%) & e.e. $(\%)$ & Conversion (\%) & e.e. $(\%)$ & Conversion (\%) \\
\hline OYE3 & $63 \pm 1.1(R)$ & $91.9 \pm 3.0$ & $47 \pm 1.2(S)$ & $88.8 \pm 2.1$ & $23 \pm 1.0(R)$ & $86.6 \pm 1.7$ \\
W116A & $>99(R)$ & $31.9 \pm 1.2$ & $43 \pm 1.0(R)$ & $7.91 \pm 0.1$ & $>99(R)$ & $9.8 \pm 0.2$ \\
S296F & $>99(R)$ & $71.1 \pm 2.0$ & $52 \pm 0.9(R)$ & $80.1 \pm 1.1$ & $72 \pm 1.5(R)$ & $80.3 \pm 1.8$ \\
H329R & $56 \pm 0.9(R)$ & $87.9 \pm 2.1$ & $32 \pm 0.7(S)$ & $86.5 \pm 2.3$ & $48 \pm 0.9(R)$ & $60.4 \pm 1.3$ \\
R38H & $55 \pm 0.8(R)$ & $89.3 \pm 2.4$ & $15 \pm 0.6(S)$ & $79.4 \pm 1.8$ & $38 \pm 1.2(R)$ & $69.2 \pm 1.7$ \\
M67L & $63 \pm 1.3(R)$ & $91.5 \pm 2.8$ & $37 \pm 1.1(S)$ & $89.0 \pm 2.3$ & $24 \pm 0.8(R)$ & $88.8 \pm 2.4$ \\
A79S & $43 \pm 1.0(R)$ & $88.5 \pm 1.9$ & $49 \pm 1.2(S)$ & $85.7 \pm 2.5$ & $22 \pm 1.3(R)$ & $86.6 \pm 2.3$ \\
V288A & $70 \pm 1.9(R)$ & $86.2 \pm 1.8$ & $38 \pm 1.3(S)$ & $84.9 \pm 2.5$ & $21 \pm 1.2(R)$ & $85.6 \pm 1.6$ \\
R12L & $63 \pm 1.2(R)$ & $94.1 \pm 2.1$ & $45 \pm 1.4(S)$ & $89.4 \pm 1.8$ & $21 \pm 0.8(R)$ & $92.8 \pm 1.9$ \\
I344K & $61 \pm 1.5(R)$ & $91.7 \pm 1.7$ & $44 \pm 0.8(S)$ & $94.0 \pm 1.3$ & $20 \pm 0.7(R)$ & $88.6 \pm 1.4$ \\
I75C & $62 \pm 2.1(R)$ & $91.8 \pm 1.6$ & $57 \pm 1.6(S)$ & $85.9 \pm 2.0$ & $14 \pm 1.0(R)$ & $92.9 \pm 2.4$ \\
P77C & $62 \pm 1.1(R)$ & $90.3 \pm 2.4$ & $77 \pm 1.7(S)$ & $96.7 \pm 1.3$ & $10 \pm 0.6(R)$ & $91.8 \pm 2.6$ \\
V113A & $60 \pm 1.6(R)$ & $97.2 \pm 1.1$ & $28 \pm 0.7(S)$ & $78.8 \pm 1.5$ & $10 \pm 0.8(R)$ & $89.3 \pm 1.0$ \\
\hline
\end{tabular}

${ }^{1}$ The reaction mixture $(1 \mathrm{~mL})$ contained $20 \mathrm{mM}$ citral, $0.6 \mathrm{mM} \mathrm{NADP}^{+}, 0.15 \mathrm{U} / \mathrm{mL}$ GDH, $50 \mathrm{mM}$ glucose, $0.15 \mathrm{U} / \mathrm{mL}$ OYE3 or its variant, and $50 \mathrm{mM}$ PIPES buffer solution (pH 7.0). The stock solution of substrate was $200 \mathrm{mM}$ citral dissolved in isopropanol. The reaction was conducted in an orbital shaker $\left(200 \mathrm{rpm}, 30^{\circ} \mathrm{C}\right)$ for $11 \mathrm{~h}$. Data present mean values $\pm \mathrm{SD}$ from three independent experiments. (E)-Citral contained $97.6 \%$ geranial and $2.4 \%$ neral, $(Z)$-citral contained $98.6 \%$ neral and $1.4 \%$ geranial, and $(E / Z)$-citral contained $58.4 \%$ geranial and $41.6 \%$ neral.

Both the variants W116A and S296F showed strict $(R)$-enantioselectivity in the reduction of $(E)$-citral, and reversed the $(S)$-enantioselectivity in the reduction of $(Z)$-citral. The e.e. value in $\mathrm{W} 116 \mathrm{~A}$-mediated reduction of $(E / Z)$-citral reached up to $>99 \%$ despite lower conversion. To get detailed insights into the molecular mechanism, the substrate and $\mathrm{FMNH}_{2}$ were docked in silico into the crystal structure of OYE3 and its variants W116A and S296F. In the docking of OYE3, a conserved H191/N194 pair formed hydrogen bonds with the carbonyl oxygen of citral; a hydride was enantioselectively transferred to the substrate $\mathrm{C}_{\beta}$ atom from $\mathrm{FMNH}_{2}$; and the $\mathrm{Y} 196$ residue provided a proton to the substrate $\mathrm{C}_{\alpha}$ atom as an electron acceptor [22,30]. The docking analyses suggested that the reversed enantioselectivity in the reduction of $(Z)$-citral was due to the flipped binding orientation that placed the opposite face of the alkene above the si face of the $\mathrm{FMNH}_{2}$ cofactor (Figure 1a-c). Meanwhile, the same variant reduced $(E)$-citral with preserved $(R)$-enantioselectivity derived from the same binding orientation as wild-type OYE3 (Figure 1d-f). In addition, the decreased catalytic efficiency of W116A might be attributed to the elongated distances between the substrate $\mathrm{C}_{\beta}$ atom and $\mathrm{FMNH}_{2}$ and the weakened hydrogen bonds between the H191/N194 pair and carbonyl oxygen of citral (Figure 1b,e). 


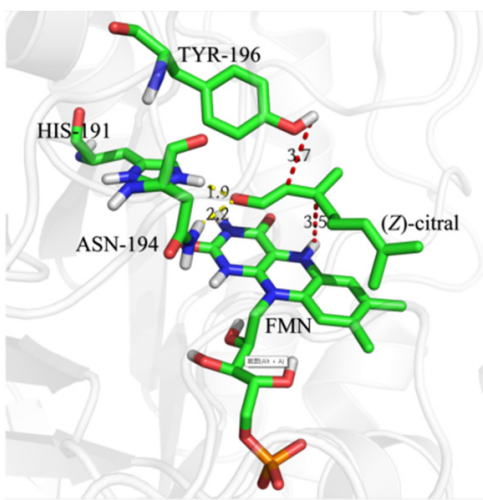

(a)

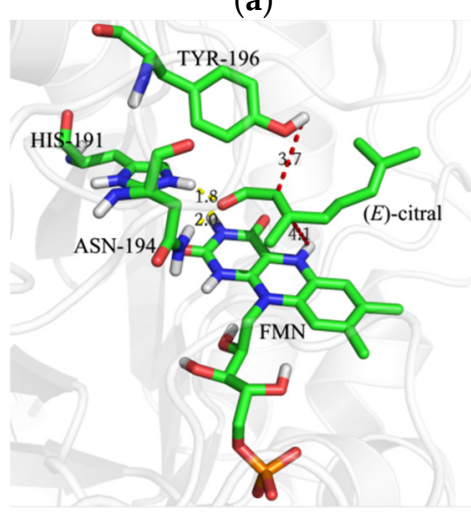

(d)

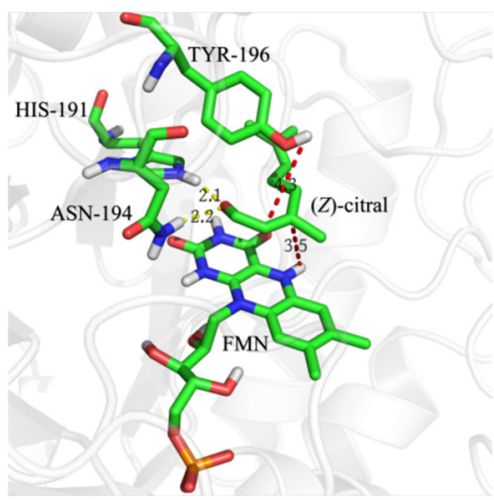

(b)

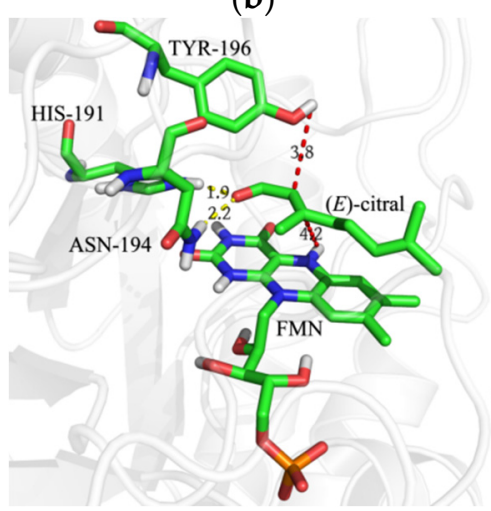

(e)

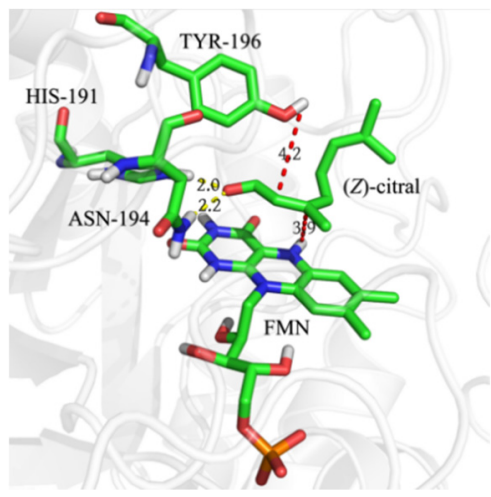

(c)

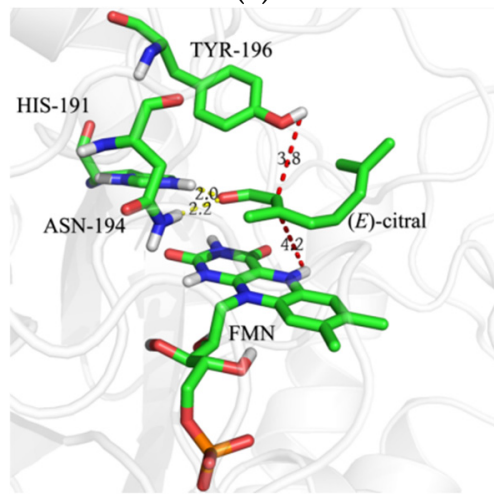

(f)

Figure 1. The binding modes of citral isomers in OYE3 and its variant S296F and W116G leading to either (R)- or (S)citronellal. (a) OYE3 and (Z)-citral; (b) W116A and (Z)-citral, flipped binding orientation; (c) S296F and (Z)-citral, flipped binding orientation; (d) OYE3 and (E)-citral; (e) W116A and (E)-citral, preserved binding orientation; (f) S296F and (E)-citral, preserved binding orientation. Green, carbon atom; blue, nitrogen atom; tangerine, oxygen atom; white, hydrogen atom; orange, phosphorus atom.

\subsection{Exploration of Double Substitution at the Sites W116 and S296 of OYE3}

To explore whether another substitution is superior to S296F, the residue S296 was replaced to be the amino acids with bulky side groups such as $\mathrm{W}$ and $\mathrm{Y}$, or those with small side groups such as A and G (Table 2). As shown in Figure S2, four variants were expressed and purified to homogeneity. All the resulting variants had no improvement of $(R)$-enantioselectivity in comparison with S296F, suggesting that subtle change at the site S296 would result in significantly different enantioselectivity [31]. Similarly, W116 was tested to be V, I, F, Y, S, and G (Figure S2). As opposed to the tested S296 variants, the enantioselectivity of the resulting W116 variants showed certain correlation with the size of side group of the substituted amino acid. The variants W116F and W116Y exhibited decreased $(R)$-enantioselectivity in the reduction of $(E)$-citral, $(Z)$-citral, or $(E / Z)$-citral. The $(R)$-enantioselectivity of W116V and W116I fell between OYE3 and the variant W116A. In the case of W116A, the increase of available free space around W116 by the insertion of Ala, which is less hindered than Trp, seemed to favor a flipped binding mode for $(Z)$ citral and promote the $(R)$-enantioselectivity up to $>99 \%$ [22]. The variants W116S and W116G showed the same strict $(R)$-enantioselectivity as W116A, but had no activity on the substrate (Z)-citral, suggesting that the site W116 was not only critical for the determination of enantioselectivity but also the discrimination of $(E)$ - and $(Z)$-citrals. 
Table 2. The catalytic performances of OYE3 and its S296X and W116X variants ${ }^{1}$.

\begin{tabular}{ccccccc}
\hline \multirow{2}{*}{ Enzyme } & \multicolumn{2}{c}{$($ E)-Citral } & \multicolumn{2}{c}{ (Z)-Citral } & \multicolumn{2}{c}{ (E/Z)-Citral } \\
\cline { 2 - 7 } & e.e. (\%) & Conversion (\%) & e.e. $(\%)$ & Conversion (\%) & e.e. (\%) & Conversion (\%) \\
\hline OYE3 & $63 \pm 1.1(R)$ & $91.9 \pm 3.0$ & $47 \pm 1.2(S)$ & $88.8 \pm 2.1$ & $23 \pm 1.0(R)$ & $86.8 \pm 1.7$ \\
S296F & $>99(R)$ & $71.1 \pm 1.2$ & $52 \pm 0.8(R)$ & $80.1 \pm 2.7$ & $72 \pm 1.8(R)$ & $80.3 \pm 1.9$ \\
S296W & $56 \pm 1.0(R)$ & $81.6 \pm 1.7$ & $1.2 \pm 0.5(R)$ & $82.6 \pm 1.9$ & $32 \pm 2.3(R)$ & $75.6 \pm 0.8$ \\
S296Y & $58 \pm 1.3(R)$ & $75.1 \pm 1.3$ & $41 \pm 1.4(S)$ & $82.8 \pm 1.4$ & $22 \pm 0.9(R)$ & $88.5 \pm 1.4$ \\
S296A & $54 \pm 0.8(R)$ & $94.3 \pm 2.0$ & $49 \pm 1.7(S)$ & $88.5 \pm 1.2$ & $15 \pm 1.4(R)$ & $89.5 \pm 2.3$ \\
S296G & $51 \pm 0.7(R)$ & $95.6 \pm 2.3$ & $44 \pm 1.1(S)$ & $71.6 \pm 0.9$ & $12 \pm 1.5(R)$ & $91.1 \pm 2.0$ \\
W116A & $>99(R)$ & $4.1 \pm 0.1$ & $>99(R)$ & $2.9 \pm 0.1$ & $>99(R)$ & $8.4 \pm 0.1$ \\
W116V & $76 \pm 1.3(R)$ & $22.5 \pm 0.4$ & $57 \pm 2.0(R)$ & $7.1 \pm 0.2$ & $>99(R)$ & $1.4 \pm 0.1$ \\
W116I & $47 \pm 1.2(R)$ & $29.0 \pm 0.7$ & $21 \pm 1.2(S)$ & $15.6 \pm 0.7$ & $44 \pm 1.8(R)$ & $24.3 \pm 0.5$ \\
W116F & $47 \pm 1.2(R)$ & $88.0 \pm 2.2$ & $67 \pm 0.9(S)$ & $14.7 \pm 0.4$ & $1.7 \pm 0.8(R)$ & $67.5 \pm 1.4$ \\
W116Y & $31 \pm 1.0(R)$ & $80.8 \pm 1.7$ & $71 \pm 1.5(S)$ & $65.1 \pm 1.9$ & $5.2 \pm 1.0(S)$ & $57.1 \pm 1.6$ \\
W116S & $>99(R)$ & $14.7 \pm 0.3$ & $/$ & $/$ & $>99(R)$ & $9.0 \pm 0.2$ \\
W116G & $>99(R)$ & $11.1 \pm 0.2$ & $/$ & $/$ & $/$ \\
\hline
\end{tabular}

${ }^{1} \mathrm{X}$ represents one of the amino acids F, W, Y, A, G, or A, V, I, F, Y, S, and G. The reaction mixture $(1 \mathrm{~mL})$ contained $20 \mathrm{mM}$ citral, $0.6 \mathrm{mM}$ $\mathrm{NADP}^{+}, 0.15 \mathrm{U} / \mathrm{mL}$ GDH, $50 \mathrm{mM}$ glucose, $0.15 \mathrm{U} / \mathrm{mL}$ OYE3 or its variant, and $50 \mathrm{mM}$ PIPES buffer solution (pH 7.0). The stock solution of substrate was $200 \mathrm{mM}$ citral dissolved in isopropanol. The reaction was conducted in an orbital shaker $\left(200 \mathrm{rpm}, 30^{\circ} \mathrm{C}\right)$ for $11 \mathrm{~h}$. Data present mean values \pm SD from three independent experiments. (E)-Citral contained $97.6 \%$ geranial and $2.4 \%$ neral, (Z)-citral contained $98.6 \%$ neral and $1.4 \%$ geranial, and $(E / Z)$-citral contained $58.4 \%$ geranial and $41.6 \%$ neral.

In contrast to the S296 variants, the catalytic activities of the W116 variants were severely decreased. To investigate the effect of the double substitutions of W116 and S296 on catalytic activity, we conducted site-directed mutagenesis of S296 to F and W116 to V, $\mathrm{S}, \mathrm{A}$, and $\mathrm{G}$, resulting in the four variants (Figure S3). All four resulting variants showed strict $(R)$-enantioselectivity in the reduction of $(E)$-citral, and had no catalytic activity on the reduction of (Z)-citral (Table 3). Among them, the only variant S296F/W116G was active in the $(E / Z)$-citral reduction, demonstrating the subtle control on the discrimination of (E)-citral and (Z)-citral.

Table 3. The catalytic performances of the S296F/W116X variants of OYE3 ${ }^{1}$.

\begin{tabular}{ccccccc}
\hline \multirow{2}{*}{ Enzyme } & \multicolumn{2}{c}{$($ E)-Citral } & \multicolumn{2}{c}{ (Z)-Citral } & \multicolumn{2}{c}{$($ E/Z)-Citral } \\
\cline { 2 - 7 } & e.e. $(\%)$ & Conversion (\%) & e.e. $(\%)$ & Conversion (\%) & e.e. $(\%)$ & Conversion (\%) \\
\hline S296F/W116V & $>99(R)$ & $11.8 \pm 0.2$ & $/$ & $/$ & $/$ & $/$ \\
S296F/W116S & $>99(R)$ & $29.3 \pm 1.0$ & $/$ & $/$ & $/$ & $/$ \\
S296F/W116A & $>99(R)$ & $8.0 \pm 0.1$ & $/$ & $/$ & $>99(R)$ & $25.3 \pm 0.5$ \\
S296F/W116G & $>99(R)$ & $31.8 \pm 0.9$ & $/$ & $/$ & $/$ & $/$ \\
\hline
\end{tabular}

${ }^{1} \mathrm{X}$ represents one of the amino acids $\mathrm{A}, \mathrm{V}, \mathrm{S}$, and $\mathrm{G}$. The reaction mixture $(1 \mathrm{~mL})$ contained $20 \mathrm{mM}$ citral, $0.6 \mathrm{mM} \mathrm{NADP}+0.15 \mathrm{U} / \mathrm{mL}^{+}$ $\mathrm{GDH}, 50 \mathrm{mM}$ glucose, $0.15 \mathrm{U} / \mathrm{mL}$ OYE3 or its variant, and $50 \mathrm{mM}$ PIPES buffer solution ( $\mathrm{pH} 7.0$ ). The stock solution of substrate was $200 \mathrm{mM}$ citral dissolved in isopropanol. The reaction was conducted in an orbital shaker $\left(200 \mathrm{rpm}, 30^{\circ} \mathrm{C}\right)$ for $11 \mathrm{~h}$. Data present mean values $\pm \mathrm{SD}$ from three independent experiments. (E)-Citral contained $97.6 \%$ geranial and $2.4 \%$ neral, (Z)-citral contained $98.6 \%$ neral and $1.4 \%$ geranial, and $(E / Z)$-citral contained $58.4 \%$ geranial and $41.6 \%$ neral.

The variant S296F/W116G exhibited lower catalytic efficiency than OYE3 in the reduction of $(E / Z)$-citral, which was supported by the determination of apparent kinetic parameters. OYE3 and its variant S296F/W116G obeyed the substrate-inhibition kinetics (Figure S4), whose inhibition might be attributed to the covalent interaction between $\alpha, \beta-$ unsaturated aldehydes and the residues of lysine and cysteine [32]. When (E)-citral was tested as substrate, the values of $K_{\mathrm{m}}, K_{\mathrm{i}}$, and $K_{\text {cat }} / K_{\mathrm{m}}$ for the variant $\mathrm{S} 296 \mathrm{~F} / \mathrm{W} 116 \mathrm{G}$ were $0.09 \mathrm{mM}, 5.85 \mathrm{mM}$, and $1.32 \mathrm{mM}^{-1} \mathrm{~s}^{-1}$, respectively (Table 4). In contrast to the variant $\mathrm{S} 296 \mathrm{~F} / \mathrm{W} 116 \mathrm{G}$, OYE3 had lower $K_{\mathrm{m}}$ and $K_{\mathrm{i}}$, but higher $K_{\text {cat }} / K_{\mathrm{m}}$, implying the "trade-off" effect between $(R)$-enantioselectivity and activity. The docking analyses indicated that the accommodation of $(E)$-citral in the active site of OYE3 and the variant S296F/W116G was similar, whereas the activity loss in the variant S296F/W116G-mediated reduction of (Z)citral might be attributed to the elongated distance of the hydroxyl group of W196 and the 
substrate $\mathrm{C}_{\alpha}$ atom as well as that of the substrate $\mathrm{C}_{\beta}$ atom and $\mathrm{FMNH}_{2}$ (Figure 2). Since the controlling on the discrimination of $(E)$-citral and (Z)-citral was so subtle, crystal structures of OYE3 and the variant S296F/W116G would be required for further interpretation on its molecular mechanism.

Table 4. Apparent kinetic parameters of OYE3 and its variant S296F/W116G ${ }^{1}$.

\begin{tabular}{ccccc}
\hline \multirow{2}{*}{ Parameter } & \multicolumn{2}{c}{ OYE3 } & \multicolumn{2}{c}{ OYE3 S296F/W116G } \\
\cline { 2 - 5 } & $($ E)-Citral & (Z)-Citral & (E)-Citral & (Z)-Citral \\
\hline$K_{\mathrm{m}}(\mathrm{mM})$ & $0.05 \pm 0.01$ & $0.07 \pm 0.01$ & $0.09 \pm 0.01$ & $/$ \\
$K_{\mathrm{i}}(\mathrm{mM})$ & $4.53 \pm 0.28$ & $5.75 \pm 0.37$ & $5.85 \pm 0.33$ & $/$ \\
$V_{\max }(\mathrm{U} / \mathrm{mg})$ & $0.16 \pm 0.03$ & $0.12 \pm 0.02$ & $0.14 \pm 0.02$ & $/$ \\
$K_{\mathrm{cat}}\left(\mathrm{s}^{-1}\right)$ & $0.13 \pm 0.02$ & $0.10 \pm 0.01$ & $0.11 \pm 0.01$ & $/$ \\
$K_{\text {cat }} / K_{\mathrm{m}}\left(\mathrm{mM}^{-1} \mathrm{~s}^{-1}\right)$ & $2.76 \pm 0.11$ & $1.49 \pm 0.08$ & $1.32 \pm 0.09$ & $/$ \\
\hline
\end{tabular}

${ }^{1}$ Data present mean values \pm SD from three independent experiments.

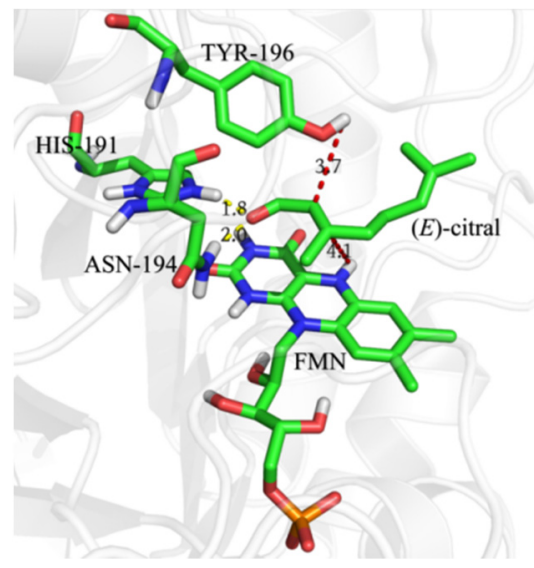

(a)

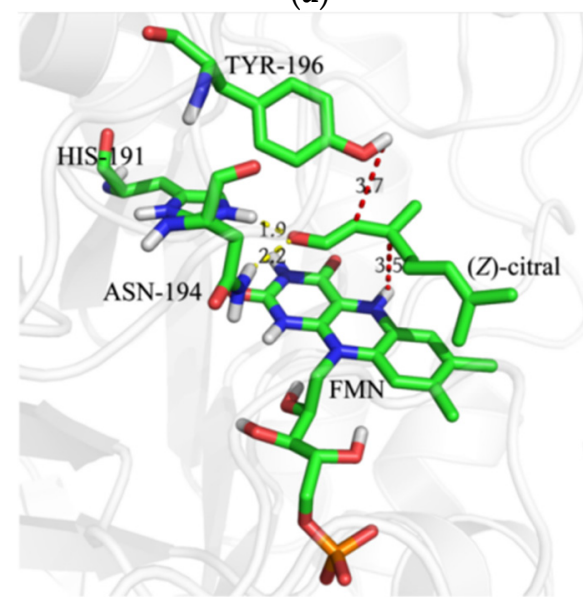

(c)

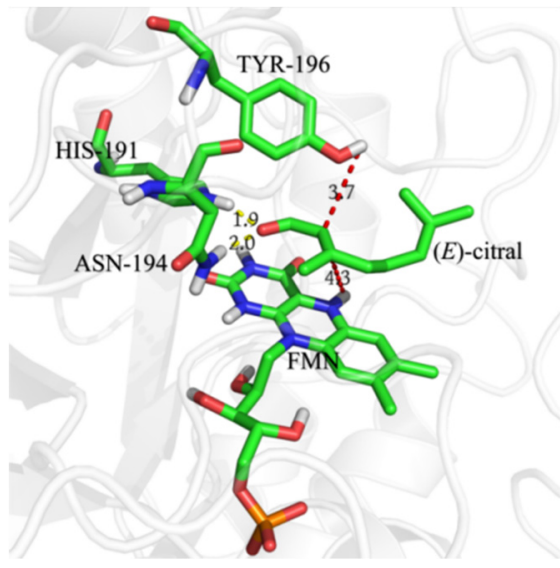

(b)

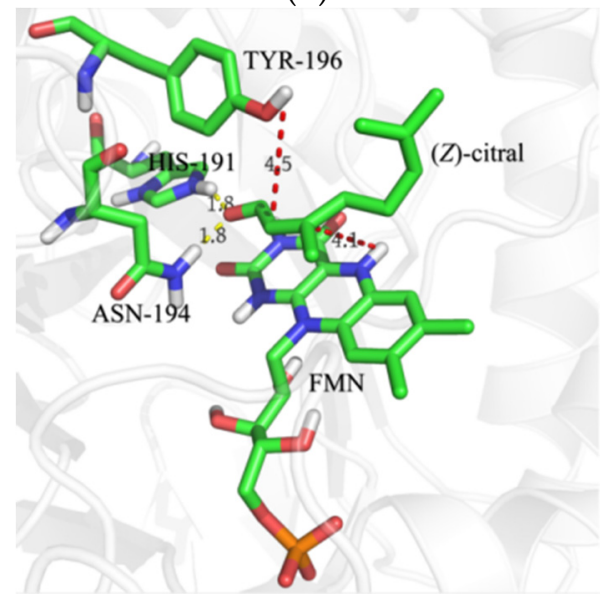

(d)

Figure 2. The docking analysis of the difference of OYE3 and its variant S296F/W116G on the utilization of citral isomer. (a) OYE3 and (E)-citral; (b) S296F/W116G and (E)-citral; (c) OYE3 and (Z)-citral; (d) S296F/W116G and (Z)-citral. Green, carbon atom; blue, nitrogen atom; tangerine, oxygen atom; white, hydrogen atom; orange, phosphorus atom.

\subsection{Asymmetric Synthesis of (R)-Citronellal and Simultaneous Resolution of (E)-Citral and} (Z)-Citral Catalyzed by the OYE3 Variant S296F/W116G and Glucose Dehydrogenase

Both OYE3 and its variant S296F/W116G were chosen to catalyze the reduction of (E/Z)-citral, and the pair of GDH from Exiguobacterium sibiricum and glucose were used to drive the regeneration of NADPH [33]. To fulfill OYE3 variant S296F/W116G- 
mediate asymmetric synthesis of $(R)$-citronellal and simultaneous resolution of $(E)$-citral and $(Z)$-citral, it is mandatory to achieve complete reduction of $(E)$-citral and then cause the retention of $(Z)$-citral. In the cascade reaction, the optimization of various factors affecting the reduction of $(E / Z)$-citral would be significantly beneficial for the conversion improvement [34,35]. To make the results more reliable, the volume of reaction mixture was adjusted to be $10 \mathrm{~mL}$ and the $\mathrm{pH}$ was kept constant using a $\mathrm{pH}$ auto-titration system. During the optimization, the effect of various factors on the variant S296F/W116G was similar to that of OYE3, but lower conversion. The influence of the reaction temperature was determined over a range of $20-45^{\circ} \mathrm{C}$, and the highest conversion was observed at $30^{\circ} \mathrm{C}$ (Figure 3a). When the temperature was greater than $30^{\circ} \mathrm{C}$, the conversion decreased as the temperature rose. To determine the optimal $\mathrm{pH}$, the reaction was carried out at different $\mathrm{pH}$ values ranging from 6.0 to 8.0 at $30^{\circ} \mathrm{C}$. The highest production was detected at $\mathrm{pH} 7.0$, and the conversion decreased sharply at $\mathrm{pH}$ values $>7.0$ (Figure $3 \mathrm{~b}$ ). The enzyme activity of OYE3 requires the co-enzymes NADPH and $\mathrm{FMNH}_{2}$. During the cascade reaction, the enzyme-bound FMN is first reduced at the expense of NADPH, then a hydride is transferred from the reduced $\mathrm{FMNH}_{2}$ to the electronically activated $\mathrm{C}_{\beta}$ position of the substrate $[18,22]$. The in situ regeneration of NADPH is achieved by using a NAD(P)H-dependent GDH and glucose as a co-substrate. On the one hand, the supplement of exogenous $\mathrm{NADP}^{+}$significantly increased the catalytic efficiency, and the $\mathrm{NADP}^{+}$concentration $(>0.4 \mathrm{mM})$ was required to maintain high catalytic activity (Figure S5a). On the other hand, the addition of FMN did not increase the conversion (Figure S5b), suggesting that the binding of FMN was tight enough for maintaining the activity of the variant S296/W116G [36]. In addition, the amounts of GDH and glucose were important for the efficiency of NADPH regeneration. When the substrate was $20 \mathrm{mM}$ (E/Z)-citral, the optimized parameters for NADPH regeneration were equal activity ratio of $\mathrm{GDH}$ and the variant S296F/W116G (Figure S6a) and $60 \mathrm{mM}$ glucose (Figure S6b).

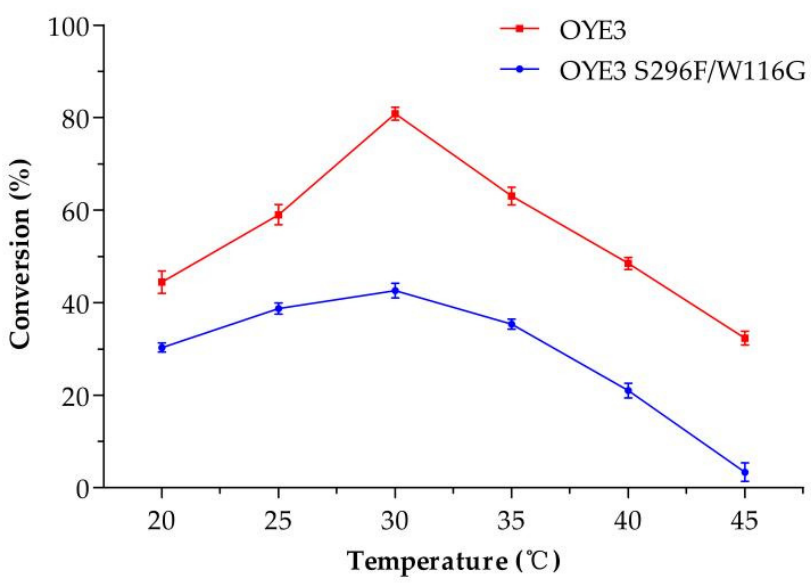

(a)

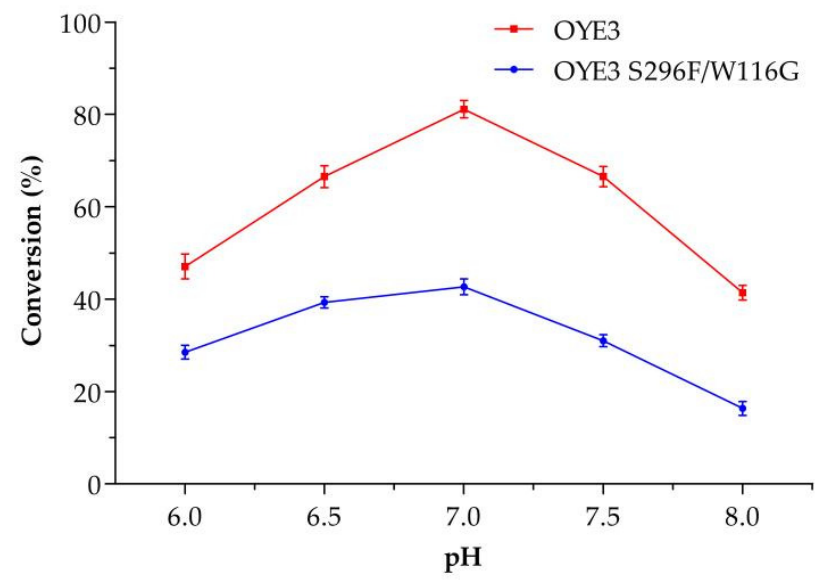

(b)

Figure 3. Determination of key factors affecting the asymmetric reduction of (E/Z)-citral to $(R)$-citronellal. The standard reaction mixture $(10 \mathrm{~mL})$ contained $20 \mathrm{mM}(E / Z)$-citral, $0.6 \mathrm{mM} \mathrm{NADP}^{+}, 0.15 \mathrm{U} / \mathrm{mL} \mathrm{GDH}, 50 \mathrm{mM}$ glucose, $0.15 \mathrm{U} / \mathrm{mL}$ of the variant S296F/W116G, and $50 \mathrm{mM}$ PIPES buffer solution (pH 7.0). The stock solution of substrate was $200 \mathrm{mM}$ citral dissolved in isopropanol. The reaction was conducted in a reactor with a pH auto-titration system at $400 \mathrm{rpm}$ for $10 \mathrm{~h}$ (OYE3) or $18 \mathrm{~h}$ (the variant S296F/W116G). The temperature was investigated from 20 to $45^{\circ} \mathrm{C}$ (a) and the pH values were explored from 6.0 to $8.0(\mathbf{b})$. Data present mean values \pm SD from three independent experiments. (E/Z)-citral contained $58.4 \%$ geranial and $41.6 \%$ neral.

Under optimized conditions, the time course of the reduction of $(E / Z)$-citral catalyzed by either OYE3 or OYE3 S296F/W116G was depicted (Figure 4). In the case of OYE3catalyzed reduction of $(E / Z)$-citral, the conversions to both $(R)$-citronellal and $(S)$-citronellal increased as $(E)$-citral and $(Z)$-citral were gradually utilized till complete consumption at 
$12 \mathrm{~h}$. Since OYE3 had the complementary enantioselectivity for $(E)$-citral and (Z)-citral, the e.e. value of $(R)$-citronellal was no greater than $40 \%$. The catalytic performance of OYE3 S296F/W116G was notably different from that of OYE3. It took $18 \mathrm{~h}$ for the variant OYE3 S296F/W116G to completely reduce $(E)$-citral, demonstrating its lower catalytic activity than that of OYE3. Most of (Z)-citral was retained and the slight decrease might be attributed to the isomerization of $(Z)$-citral to $(E)$-citral. As anticipated, $(S)$-citronellal was not detectable and the e.e. values of $(R)$-citronellal remained $>99 \%$, verifying that the proposed approach for asymmetric synthesis of $(R)$-citronellal and simultaneous resolution of $(E)$-citral and $(Z)$-citral was feasible.

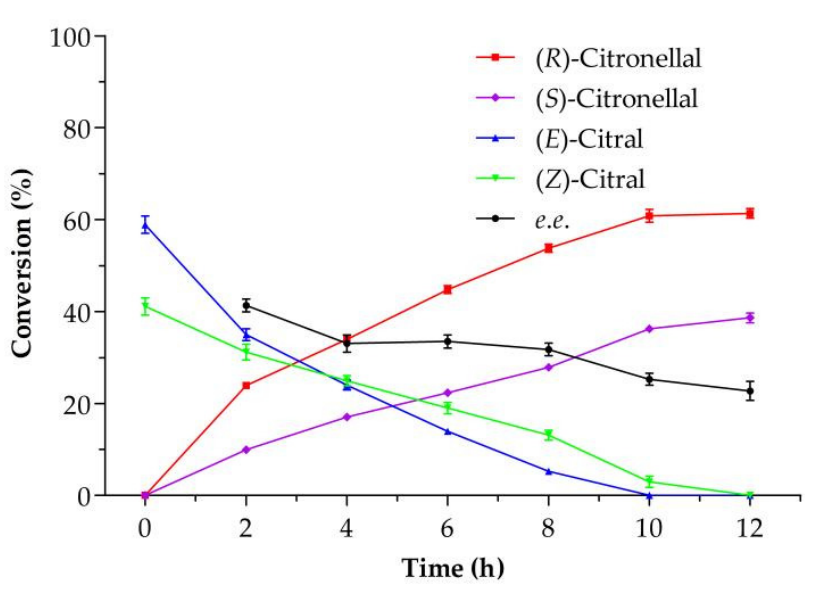

(a)

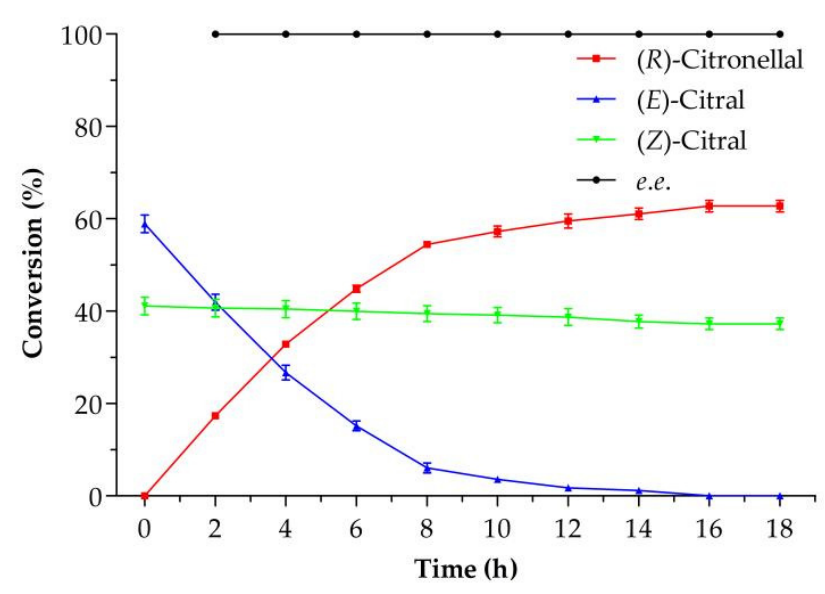

(b)

Figure 4. Time courses of asymmetric reduction of (E/Z)-citral to $(R)$-citronellal. (a) OYE3 and GDH as biocatalyst; (b) the variant OYE3 S296F/W116G and GDH as biocatalyst. The standard reaction mixture (10 mL) contained $20 \mathrm{mM}(E / \mathrm{Z})$-citral, $0.4 \mathrm{mM} \mathrm{NADP}^{+}, 0.15 \mathrm{U} / \mathrm{mL}$ GDH, $50 \mathrm{mM}$ glucose, $0.15 \mathrm{U} / \mathrm{mL}$ of the variant S296F/W116G, and $50 \mathrm{mM}$ PIPES buffer solution ( $\mathrm{pH}$ 7.0). The stock solution of substrate was $200 \mathrm{mM}$ citral dissolved in isopropanol. The reaction was conducted in a reactor with a $\mathrm{pH}$ auto-titration system at $400 \mathrm{rpm}$ and $30^{\circ} \mathrm{C}$ for $12 \mathrm{~h}$ (OYE3) or $18 \mathrm{~h}$ (the variant S296F/W116G). Data present mean values \pm SD from three independent experiments. ( $E / Z)$-citral contained $58.4 \%$ geranial and $41.6 \%$ neral.

\section{Materials and Methods}

\subsection{Genes, Organisms, and Chemicals}

The genes encoding OYE3 and glucose dehydrogenase from Exiguobacterium sibiricum were codon-optimized and then synthesized by Tsingke Biotechnology Co., Ltd. (Hangzhou, China) (Figure S7). The pET28b expression vector was used for over-expression of the enzyme OYE3 and GDH, and the E. coli strain BL21(DE3) was used as the host. E. coli cultures were grown routinely in Luria Bertani (LB) medium at $37^{\circ} \mathrm{C}$ for $12 \mathrm{~h}$.

(Z)-citral and (E)-citral were prepared by a previously-described procedure [11,37]. Other chemicals, including the standards, were of analytical grade and purchased from Sangon Biotech Co. Ltd. (Shanghai, China) or Sigma-Aldrich (Shanghai, China). The site-directed mutagenesis kit was obtained from Vazyme Biotech Co., Ltd. (Nanjing, China). The Ni-NTA-HP resin column for protein purification was purchased from GE Healthcare Life Sciences (Shanghai, China).

\subsection{Over-Expression and Purification of OYE3 and GDH}

The gene encoding OYE3 (Figure S7) was inserted into the sites Nco I/Xho I of the plasmid pET28b, resulting in the plasmid pET28b-oye3. The plasmid pET28b-oye3 was transformed into E. coli BL21 (DE3) competent cells, resulting in the strain E. coli BL21(DE3)/pET28b-oye3. The cells containing pET28b-oye3 were cultured in the LB medium with $100 \mu \mathrm{g} / \mathrm{mL}$ kanamycin at $37^{\circ} \mathrm{C}$ and $200 \mathrm{rpm}$ until the $\mathrm{OD}_{600}$ of 0.6 , and $0.2 \mathrm{mM}$ isopropyl $\beta$-D-1-thiogalactopyranoside (IPTG) was supplemented for the induction 
at $25{ }^{\circ} \mathrm{C}$ and $160 \mathrm{rpm}$. After $12 \mathrm{~h}$ of induction, E. coli cells were harvested by centrifugation and further washed using $50 \mathrm{mM}$ Tris- $\mathrm{HCl}$ buffer ( $\mathrm{pH} \mathrm{8.0)}$. The productivity of OYE3 was $2.42 \mathrm{U}$ per gram of wet cells. The cells were disrupted through ultrasonication for $10 \mathrm{~min}$, and the cell debris was removed by centrifugation to result in a clear cell extract. The crude cell extracts containing OYE3 was applied to a Ni-NTA chelating affinity column equilibrated with the binding buffer $(5 \mathrm{mM}$ imidazole and $300 \mathrm{mM} \mathrm{NaCl}$ dissolved in $50 \mathrm{mM}$ Tris- $\mathrm{HCl}, \mathrm{pH} 8.0$ ). Unbound proteins were washed off by the application of the binding buffer. The OYE3 was eluted with $100 \mathrm{mM}$ imidazole in $50 \mathrm{mM}$ Tris- $\mathrm{HCl}(\mathrm{pH} 8.0)$, desalted with $50 \mathrm{mM}$ Tris- $\mathrm{HCl}$ buffer $(\mathrm{pH} 8.0)$ by ultrafiltration, and then stored at $-20{ }^{\circ} \mathrm{C}$ for further study.

The gene encoding GDH (Figure S7) was inserted into the sites Nde I/Xho I of the plasmid pET28b, resulting in the plasmid pET28b-gdh. Following the similar procedure to OYE3, the cells harboring pET28b- $g d h$ was induced and the enzyme GDH was purified for further use. The purity of the purified enzymes was visualized through SDS-PAGE analysis using a $12 \%$ resolving gel [38].

\subsection{Construction of OYE3 Variants by Site-Directed Mutagenesis}

The site-directed mutagenesis was performed as previously described [11]. PCR amplification to introduce substitution was performed in $30 \mu \mathrm{L}$ of standard PCR mixture with $50 \mathrm{ng}$ of template plasmid DNA and 15 pmol each of the appropriate set of primers using the following temperature cycle; $5 \mathrm{~min}$ at $95^{\circ} \mathrm{C}$, followed by 30 cycles of $95^{\circ} \mathrm{C}$ for $15 \mathrm{~s}$, appropriate annealing temperature $\left(55-61^{\circ} \mathrm{C}\right)$ for $15 \mathrm{~s}$, and $72{ }^{\circ} \mathrm{C}$ for $1 \mathrm{~min}$, and the final extension of $5 \mathrm{~min}$ at $72{ }^{\circ} \mathrm{C}$. The plasmid pET28b-oye 3 was used as template DNA in the single substitution, while the creation of double substitutions was based on the gene encoding the variant OYE3 S296F as the template. The primer sets for single or double substitutions were shown in Tables S1-S3. The amplified PCR fragments were digested with the restriction enzyme $D p n \mathrm{I}$ at $37^{\circ} \mathrm{C}$ for $1 \mathrm{~h}$, and then the digested DNA was directly introduced into E. coli strain BL21(DE3). Each constructed plasmid was confirmed by sequencing. Expression and purification of the resulting OYE3 variants were conducted using the same procedure as OYE3. Specifically, the productivity of OYE3 S296F/W116G was $1.74 \mathrm{U}$ per gram of wet cells.

\subsection{Assays of Glucose Dehydrogenase and Old Yellow Enzymes}

Activities of the purified OYEs and GDH were measured at $30{ }^{\circ} \mathrm{C}$ by monitoring the change of the absorbance at $340 \mathrm{~nm}$. The enzyme assay for OYEs was carried out in triplicate in a reaction mixture $(1 \mathrm{~mL})$ composed of $2 \mathrm{mM}(E)$-citral and $0.2 \mathrm{mM}$ NADPH in $100 \mathrm{mM}$ PIPES buffer ( $\mathrm{pH}$ 7.0). The enzyme assay for GDH was carried out in triplicate in a reaction mixture $(1 \mathrm{~mL})$ composed of $5 \mathrm{mM}$ glucose and $0.4 \mathrm{mM} \mathrm{NADP}^{+}$in $100 \mathrm{mM}$ PIPES buffer ( $\mathrm{pH}$ 7.0). Both reactions were started by the addition of the enzyme ( $1 \mu \mathrm{g}$ for GDH, $5 \mu \mathrm{g}$ for OYE3 or its variants). One unit of the activity is defined as formation or oxidation of $1 \mu \mathrm{mol}$ NADPH per min. The protein concentrations of all samples were determined using the BCA reagent with bovine serum albumin as the standard protein [39].

Apparent kinetic parameters were determined using different concentrations of $(E)$ citral and (Z)-citral. Concentrations of $(E)$-citral and $(Z)$-citral were 0.01, 0.05, 0.1, 0.5, 1, 2, $5,10,20$, and $50 \mathrm{mM}$. According to substrate-inhibition kinetics, apparent values of $K_{\mathrm{m}}$, $K_{i}$, and $V_{\max }$ were calculated using the curve fittings of the software Prism 7.2 (GraphPad Software, San Diego, CA, USA).

\subsection{Homology Modeling and Molecular Docking}

Using the crystal structure of OYE3 from S. cerevisiae S288C (PDB number: 5v4p, resolution $1.88 \AA$ ), molecular docking simulation was performed using AutoDock Vina under the default docking parameters [40]. Point charges were initially assigned according to the AMBER03 force field and then damped to mimic the less polar Gasteiger charges [41]. (E)-citral or (Z)-citral acted as a ligand to molecular docking with OYE3, and the calculation 
of geometric parameters and ligand structure was performed by ChemBioDraw 12.0 (CambridgeSoft, Cambridge, MA, USA). All homology models of OYE3 variants were built using the "BuildModel" tool implemented in FoldX software with the model of OYE3 as a template [42-44]. To make the results more accurate, 20 consecutive runs were performed and the highest ranked score from each run was used to calculate the average score of each flexible ligand configuration. The docking result with the minimal binding energy value was selected from 100 predictions. The visualization of the resulting substrate-enzyme complexes was processed using the PyMol software [45].

3.6. Investigation of Catalytic Performance of OYE3 and Its Variants in the Reduction of (E)-, (Z)-, or (E/Z)-Citral

To determine catalytic performance of OY3 and its variants, the standard reaction mixture $(1 \mathrm{~mL})$ contained $20 \mathrm{mM}$ citral, $0.6 \mathrm{mM} \mathrm{NADP}^{+}, 0.15 \mathrm{U} / \mathrm{mL} \mathrm{GDH}, 50 \mathrm{mM}$ glucose, $0.15 \mathrm{U} / \mathrm{mL}$ OYE3 or its variant, and $50 \mathrm{mM}$ PIPES buffer solution ( $\mathrm{pH}$ 7.0). The substrate included (E)-citral, (Z)-citral, or (E/Z)-citral, whose stock solution was $200 \mathrm{mM}$ substrate in isopropanol. The reaction mixture was incubated in an orbital shaker $\left(200 \mathrm{rpm}, 30^{\circ} \mathrm{C}\right)$ for $11 \mathrm{~h}$, and then extracted using an equal volume of ethyl acetate at $30^{\circ} \mathrm{C}$ and $200 \mathrm{rpm}$ for $2 \mathrm{~h}$. After extraction and centrifugation (12,000 rpm, $1 \mathrm{~min})$, the solvent phase was collected, dried over anhydrous sodium sulfate, and subjected to GC analyses as previously described [11]. All reactions were carried out in triplicate.

The GC analyses of substrates and products were conducted using the GC (Agilent 6890N) equipped with an FID detector and chiral capillary BGB-174 column (BGB Analytik, Switzerland, $30 \mathrm{~m}$ length, $250 \mu \mathrm{m}$ inner diameter, $0.25 \mu \mathrm{m}$ film thickness). The flow rate and split ratio of $\mathrm{N}_{2}$ as the carrier gas were set as $2 \mathrm{~mL} / \mathrm{min}$ and 1:49, respectively. The temperatures for both injector and detector were set as $250{ }^{\circ} \mathrm{C}$. The column temperature program was listed as follows: initial temperature of $90^{\circ} \mathrm{C}$ for $25 \mathrm{~min}, 20^{\circ} \mathrm{C} / \mathrm{min}$ ramp to $160{ }^{\circ} \mathrm{C}$ for $2 \mathrm{~min}$, and $20^{\circ} \mathrm{C} / \mathrm{min}$ ramp to $180^{\circ} \mathrm{C}$ for $3 \mathrm{~min}$. The injection volume was $1 \mu \mathrm{L}$. The retention times of $(S)$-citronellal, $(R)$-citronellal, (Z)-citral and $(E)$-citral were 22.5, 23.0, 29.2, and $30.2 \mathrm{~min}$ (Figure S8).

\subsection{Identification of Key Factors for S296F/W116G Mediated-Reduction of (E)-Citral}

To identify key factors for S296F/W116G mediated-reduction of (E/Z)-Citral, the standard reaction mixture $(10 \mathrm{~mL})$ contained $20 \mathrm{mM}(E / Z)$-citral, $0.6 \mathrm{mM} \mathrm{NADP}^{+}, 0.15 \mathrm{U} / \mathrm{mL}$ $\mathrm{GDH}, 50 \mathrm{mM}$ glucose, $0.15 \mathrm{U} / \mathrm{mL}$ the variant S296F/W116G, and $50 \mathrm{mM}$ PIPES buffer solution (pH 7.0). The reaction was conducted at $400 \mathrm{rpm}$ and $30^{\circ} \mathrm{C}$ for $10 \mathrm{~h}$ (OYE3) or $18 \mathrm{~h}$ (the variant S296F/W116G) in a reactor with $\mathrm{pH}$-constant auto-titration system. The solution for $\mathrm{pH}$ auto-titration was $1 \mathrm{M} \mathrm{NaOH}$. The optimal temperature of $(E)$-citral reduction was determined at a series of temperatures ranging from 20 to $45^{\circ} \mathrm{C}$. The optimal pH was determined over a range of $\mathrm{pH} 6.0$ to 8.0 at $30^{\circ} \mathrm{C}$. The concentrations of $\mathrm{NADP}^{+}$were explored within the range of 0 to $1 \mathrm{mM}$. The optimal glucose concentration was determined over a range of 1 to $100 \mathrm{mM}$. The activity ratio of GDH and the variant S296F/W116G was tested to be 1:4, 2:4, 4:4, 6:4, or 8:4. After optimization, the time courses OYE3 and the variant OYE3 S296F/W116G-mediated reduction of $(E / Z)$-citral were investigated in the reaction mixture as below: $20 \mathrm{mM}(E / Z)$-citral, $0.4 \mathrm{mM} \mathrm{NADP}^{+}, 0.15 \mathrm{U} / \mathrm{mL} \mathrm{GDH}, 60 \mathrm{mM}$ glucose, $0.15 \mathrm{U} / \mathrm{mL}$ OYE3, or the variant S296F/W116G, and $50 \mathrm{mM}$ PIPES buffer solution (pH 7.0). The reactions for OYE3 and the variant OYE3 S296F/W116G mediated reduction of $(E / Z)$-citral were conducted at $400 \mathrm{rpm}$ and $30^{\circ} \mathrm{C}$ for $12 \mathrm{~h}$ and $18 \mathrm{~h}$, respectively. The reaction mixture was sampled every $2 \mathrm{~h}$. The samples were extracted using an equal volume of ethyl acetate at $30^{\circ} \mathrm{C}$ and $200 \mathrm{rpm}$ for $2 \mathrm{~h}$. Then, the solvent phase was collected, dried over anhydrous sodium sulfate, and subjected to GC analyses as described in the Section 3.6. All reactions were carried out in triplicate.

\section{Conclusions}

The enzyme OYE3 was engineered through semi-rational design to improve $(R)$ enantioselectivity in the reduction of $(E / Z)$-citral to $(R)$-citronellal. The substitution of 
S296 to F resulted in the remarkable improvement of $(R)$-enantioselectivity. The variant W116A showed strict $(R)$-enantioselectivity in the reduction of $(E)$-citral, $(Z)$-citral or $(E / Z)$-citral. To the best of our knowledge, this is the first report to completely reverse $(S)$-enantioselectivity to $(R)$-enantioselectivity in the OYE family. Interestingly, the further double substitution variant W116A/S296F was capable of discriminating (E)-citral and (Z)citral, indicating that the sites W116 and S296 were pivotal for not only the determination of enantioselectivity, but also the discrimination of citral isomers. Using the variant OYE3 S296F/W116G and GDH as biocatalyst, a novel cascade reaction was achieved to offer two isomers in the $(E / Z)$-citral reduction: enantio-pure $(R)$-citronellal and the retained $(Z)$-citral after complete consumption of $(E)$-citral.

Supplementary Materials: The following are available online, Table S1: The primer information of site-directed mutagenesis of OYE3, Table S2: The primer information of site-directed mutagenesis of W116 and S296 in OYE3, Table S3: The primer information of combinatorial mutagenesis of W116 and S296 in OYE3, Figure S1: SDS-PAGE (12\%) analysis of OYE3 and 12 purified OYE3 variants, Figure S2: SDS-PAGE (12\%) analysis of OYE3 and 12 purified OYE3 variants with single substitution at site W116 or S296, Figure S3: SDS-PAGE (12\%) analysis of 4 purified OYE3 variants with double substitution at sites W116 and S296, Figure S4: Apparent kinetic parameter determination of OYE3 and its variant S296F/W116G, Figure S5: Effect of NADP ${ }^{+}$and FMN on the reduction of (E/Z)-citral to $(R)$-citronellal, Figure S6: Effect of glucose dehydrgenase (a) and glucose (b) on the reduction of $(E / Z)$-citral to $(R)$-citronellal, Figure S7: The codon-optimized nucleotide sequences encoding old yellow enzyme OYE3 from Saccharomyces cerevisiae S288C and glucose dehydrogenase from Exiguobacterium sibiricum, Figure S8: The GC chromatogram of standard substrates (a) and standard products (b).

Author Contributions: Conceptualization, X.Y.; Methodology, software, validation, formal analysis, investigation, resources, data curation, T.W., R.W., Y.F., L.J., Y.J., D.Y., Z.L., M.H., X.L., C.L. and X.Y.; Writing-original draft preparation, T.W. and X.Y.; Writing-review and editing, T.W., R.W., Y.F., L.J., Y.J., D.Y., Z.L., M.H., X.L., C.L. and X.Y.; Visualization, X.Y.; Supervision, X.Y.; Project administration, T.W. and X.Y.; Funding acquisition, X.Y. All authors have read and agreed to the published version of the manuscript.

Funding: This work was supported by the Natural Science Foundation of Zhejiang Province, China (No. LY17B020012).

Conflicts of Interest: The authors declare no conflict of interest.

Sample Availability: Samples of the compounds are not available from the authors.

\section{References}

1. Lenardão, E.J.; Botteselle, G.V.; de Azambuja, F.; Perin, G.; Jacob, R.G. Citronellal as key compound in organic synthesis. Tetrahedron 2007, 63, 6671-6712. [CrossRef]

2. Siedenburg, G.; Jendrossek, D.; Breuer, M.; Juhls, B.; Pleiss, J.; Seitz, M.; Klebensberger, J.; Hauer, B. Activation-independent cyclization of monoterpenoids. Appl. Environ. Microbiol. 2012, 78, 1055-1062. [CrossRef]

3. Siedenburg, G.; Breuer, M.; Jendrossek, D. Prokaryotic squalene-hopene cyclases can be converted to citronellal cyclases by single amino acid exchange. Appl. Microbiol. Biotechnol. 2013, 97, 1571-1580. [CrossRef]

4. Itoh, H.; Maeda, H.; Yamada, S.; Hori, Y.; Mino, T.; Sakamoto, M. Kinetic resolution of citronellal by chiral aluminum catalysts: L-menthol synthesis from citral. Org. Chem. Front. 2014, 1, 1107-1115. [CrossRef]

5. Tani, K.; Yamagata, T.; Akutagawa, S.; Kumobayashi, H.; Taketomi, T.; Takaya, H.; Miyashita, A.; Noyori, R.; Otsuka, S. Highly enantioselective isomerization of prochiral allylamines catalyzed by chiral diphosphine Rhodium(I) complexes: Preparation of optically active enamines. J. Am. Chem. Soc. 1984, 106, 5208-5217. [CrossRef]

6. Sayo, N.; Matsumoto, T. Method for Producing L-Menthol. U.S. Patent US6342644, 29 January 2002.

7. Nowak, R.; Michler, M.; Reiss, I.; Winkel, R. Menthol-Containing Solids Composition. U.S. Patent US8524257, 3 September 2013.

8. Zheng, L.; Lin, J.; Zhang, B.; Kuang, Y.; Wei, D. Identification of a yeast old yellow enzyme for highly enantioselective reduction of citral isomers to $(R)$-citronellal. Bioresour. Bioprocess. 2018, 5, 9. [CrossRef]

9. de María, P.D.; de Gonzalo, G.; Alcántara, A.R. Biocatalysis as useful tool in asymmetric synthesis: An assessment of recently granted patents (2014-2019). Catalysts 2019, 9, 802. [CrossRef]

10. Wu, S.; Snajdrova, R.; Moore, J.C.; Baldenius, K.; Bornscheuer, U.T. Biocatalysis: Enzymatic Synthesis for Industrial Applications. Angew. Chem. Int. Ed. 2021, 60, 88-119. [CrossRef] [PubMed] 
11. Ying, X.; Yu, S.; Huang, M.; Wei, R.; Meng, S.; Cheng, F.; Yu, M.; Ying, M.; Zhao, M.; Wang, Z. Engineering the enantioselectivity of yeast old yellow enzyme OYE2y in asymmetric reduction of (E/Z)-citral to $(R)$-citronellal. Molecules 2019, 24, 1057. [CrossRef] [PubMed]

12. Scholtissek, A.; Tischler, D.; Westphal, A.H.; Van Berkel, W.J.H.; Paul, C.E. Old yellow enzyme-catalysed asymmetric hydrogenation: Linking family roots with improved catalysis. Catalysts 2017, 7, 130. [CrossRef]

13. Tentori, F.; Bavaro, T.; Brenna, E.; Colombo, D.; Monti, D.; Semproli, R.; Ubiali, D. Immobilization of Old Yellow Enzymes via covalent or coordination bonds. Catalysts 2020, 10, 260. [CrossRef]

14. Wolken, W.A.M.; ten Have, R.; van der Werf, M.J. Amino acid-catalyzed conversion of citral: Cis-trans isomerization and its conversion into 6-methyl-5-hepten-2-one and acetaldehyde. J. Agric. Food Chem. 2000, 48, 5401-5405. [CrossRef] [PubMed]

15. Müller, A.; Hauer, B.; Rosche, B. Asymmetric alkene reduction by yeast old yellow enzymes and by a novel Zymomonas mobilis reductase. Biotechnol. Bioeng. 2007, 98, 22-29. [CrossRef]

16. Amato, E.D.; Stewart, J.D. Applications of protein engineering to members of the old yellow enzyme family. Biotechnol. Adv. 2015, 33, 624-631. [CrossRef]

17. Kataoka, M.; Miyakawa, T.; Shimizu, S.; Tanokura, M. Enzymes useful for chiral compound synthesis: Structural biology, directed evolution, and protein engineering for industrial use. Appl. Microbiol. Biotechnol. 2016, 100, 5747-5757. [CrossRef]

18. Toogood, H.S.; Scrutton, N.S. Discovery, characterization, engineering, and applications of ene-reductases for industrial biocatalysis. ACS Catal. 2018, 8, 3532-3549. [CrossRef] [PubMed]

19. Shi, Q.; Wang, H.; Liu, J.; Li, S.; Guo, J.; Li, H.; Jia, X.; Huo, H.; Zheng, Z.; You, S.; et al. Old yellow enzymes: Structures and structure-guided engineering for stereocomplementary bioreduction. Appl. Microbiol. Biotechnol. 2020, 104, 8155-8170. [CrossRef] [PubMed]

20. Padhi, S.K.; Bougioukou, D.J.; Stewart, J.D. Site-saturation mutagenesis of tryptophan 116 of Saccharomyces pastorianus old yellow enzyme uncovers stereocomplementary variants. J. Am. Chem. Soc. 2009, 131, 3271-3280. [CrossRef] [PubMed]

21. Brenna, E.; Crotti, M.; Gatti, F.G.; Monti, D.; Parmeggiani, F.; Powell, R.W., III; Santangelo, S.; Stewart, J.D. Opposite enantioselectivity in the bioreduction of (Z)- $\beta$-aryl-bcyanoacrylates mediated by the tryptophan 116 mutants of old yellow enzyme 1 : Synthetic approach to (R)- and (S)- $\beta$-aryl-glactams. Adv. Synth. Catal. 2015, 357, 1849-1860. [CrossRef]

22. Crotti, M.; Parmeggiani, F.; Ferrandi, E.E.; Gatti, F.G.; Sacchetti, A.; Riva, S.; Brenna, E.; Monti, D. Stereoselectivity switch in the reduction of $\alpha$-alkyl- $\beta$-arylenones by structure-guided designed variants of the ene reductase OYE1. Front. Bioeng. Biotechnol. 2019, 7, 89. [CrossRef]

23. Walton, A.Z.; Sullivan, B.; Patterson-Orazem, A.C.; Stewart, J.D. Residues controlling facial selectivity in an alkene reductase and semirational alterations to create stereocomplementary variants. ACS Catal. 2015, 4, 2307-2318. [CrossRef]

24. Rüthlein, E.; Classen, T.; Dobnikar, L.; Schölzel, M.; Pietruszka, J. Finding the selectivity switch-A rational approach towards stereocomplementary variants of the ene reductase YqjM. Adv. Synth. Catal. 2015, 357, 1775-1786. [CrossRef]

25. Yin, B.; Deng, J.; Lim, L.; Yuan, Y.A.; Wei, D. Structural insights into stereospecific reduction of $\alpha$, $\beta$-unsaturated carbonyl substrates by old yellow enzyme from Gluconobacter oxydans. Biosci. Biotechnol. Biochem. 2015, 79, 410-421. [CrossRef] [PubMed]

26. Kress, N.; Rapp, J.; Hauer, B. Enantioselective reduction of citral isomers in NCR ene reductase: Analysis of an active site mutant library. ChemBioChem 2017, 18, 717-720. [CrossRef]

27. Bougioukou, D.J.; Walton, A.Z.; Stewart, J.D. Towards preparative-scale, biocatalytic alkene reductions. Chem. Commun. 2010, 46, 8558-8560. [CrossRef]

28. Müller, A.; Hauer, B.; Rosche, B. Enzymatic reduction of the $\alpha, \beta$-unsaturated carbon bond in citral. J. Mol. Catal. B Enzym. 2006, 38, 126-130. [CrossRef]

29. Hall, M.; Stueckler, C.; Hauer, B.; Stuermer, R.; Friedrich, T.; Breuer, M.; Kroutil, W.; Faber, K. Asymmetric bioreduction of activated $\mathrm{C}=\mathrm{C}$ bonds using Zymomonas mobilis NCR enoate reductase and old yellow enzymes OYE 1-3 from yeasts. Eur. J. Org. Chem. 2008, 2008, 1511-1516. [CrossRef]

30. Peters, C.; Frasson, D.; Sievers, M.; Buller, R. Novel old yellow enzyme subclasses. ChemBioChem 2019, 20, 1569-1577. [CrossRef] [PubMed]

31. Pompeu, Y.A.; Sullivan, B.; Stewart, J.D. X-ray crystallography reveals how subtle changes control the orientation of substrate binding in an alkene reductase. ACS Catal. 2013, 3, 2376-2390. [CrossRef]

32. Haridas, M.; Abdelraheem, E.M.M.; Hanefeld, U. 2-Deoxy-D-ribose-5-phosphate aldolase (DERA): Applications and modifications. Appl. Microbial. Biotechnol. 2018, 102, 9959-9971. [CrossRef] [PubMed]

33. Zhao, M.; Gao, L.; Zhang, L.; Bai, Y.; Chen, L.; Yu, M.; Cheng, F.; Sun, J.; Wang, Z.; Ying, X. Asymmetric reduction of ketopantolactone using a strictly $(R)$-stereoselective carbonyl reductase through efficient NADPH regeneration and the substrate constant-feeding strategy. Biotechnol. Lett. 2017, 39, 1741-1746. [CrossRef]

34. Ying, X.; Wang, C.; Shao, S.; Wang, Q.; Zhou, X.; Bai, Y.; Chen, L.; Lu, C.; Zhao, M.; Wang, Z. Efficient Oxidation of Methyl Glycolate to Methyl Glyoxylate Using a Fusion Enzyme of Glycolate Oxidase, Catalase and Hemoglobin. Catalysts 2020, 10, 943. [CrossRef]

35. Qiao, Y.; Wang, C.; Zeng, Y.; Wang, T.; Qiao, J.; Lu, C.; Wang, Z.; Ying, X. Efficient whole-cell oxidation of $\alpha, \beta$-unsaturated alcohols to $\alpha, \beta$-unsaturated aldehydes through the cascade biocatalysis of alcohol dehydrogenase, NADPH oxidase and hemoglobin. Microb. Cell Fact. 2021, 20, 17. [CrossRef] 
36. Jia, Y.; Wang, Q.; Qiao, J.; Feng, B.; Zhou, X.; Jin, L.; Feng, Y.; Yang, D.; Lu, C.; Ying, X. Cascading Old Yellow Enzyme, Alcohol Dehydrogenase and Glucose Dehydrogenase for Selective Reduction of (E/Z)-Citral to (S)-Citronellol. Catalysts 2021, 11, 931. [CrossRef]

37. Tsuboi, S.; Ishii, N.; Sakai, T.; Tari, I.; Utaka, M. Oxidation of alcohols with electrolytic manganese dioxide. Its application for the synthesis of insect pheromones. Bull. Chem. Soc. Jpn. 1990, 63, 1888-1893. [CrossRef]

38. Shapiro, A.L.; Viñuela, E.; Maizel, J.V. Molecular weight estimation of polypeptide chains by electrophoresis in SDSpolyacrylamide gels. Biochem. Biophys. Res. Commun. 1967, 28, 815-820. [CrossRef]

39. Smith, P.K.; Krohn, R.I.; Hermanson, G.T.; Mallia, A.K.; Gartner, F.H.; Provenzano, M.D.; Fujimoto, E.K.; Goeke, N.M.; Olson, B.J.; Klenk, D.C. Measurement of protein using bicinchoninic acid. Anal. Biochem. 1985, 150, 76-85. [CrossRef]

40. Trott, O.; Olson, A.J. AutoDock Vina: Improving the speed and accuracy of docking with a new scoring function, efficient optimization, and multithreading. J. Comput. Chem. 2010, 31, 455-461. [CrossRef] [PubMed]

41. Duan, Y.; Wu, C.; Chowdhury, S.; Lee, M.C.; Xiong, G.M.; Zhang, W.; Yang, R.; Cieplak, P.; Luo, R.; Lee, T.; et al. A point-charge force field for molecular mechanics simulations of proteins based on condensed-phase quantum mechanical calculations. $J$. Comput. Chem. 2003, 24, 1999-2012. [CrossRef] [PubMed]

42. Schymkowitz, J.; Borg, J.; Stricher, F.; Nys, R.; Rousseau, F.; Serrano, L. The FoldX web server: An online force field. Nucleic Acids Res. 2005, 33, W382-W388. [CrossRef] [PubMed]

43. Arnold, K.; Bordoli, L.; Kopp, J.; Schwede, T. The SWISS-MODEL workspace: A web-based environment for protein structure homology modelling. Bioinformatics 2006, 22, 195-201. [CrossRef] [PubMed]

44. Schwede, T.; Kopp, J.; Guex, N.; Peitsch, M.C. SWISS-MODEL: An antomated protein homology-modeling server. Nucleic Acids Res. 2003, 31, 3381-3385. [CrossRef] [PubMed]

45. Seeliger, D.; de Groot, B.L. Ligand docking and binding site analysis with PyMOL and Autodock/Vina. J. Comput. Aided Mol. Des. 2010, 24, 417-422. [CrossRef] [PubMed] 